\title{
Commonness and rarity of species: Does species' rank influence contribution to functional diversity?
}

\section{Jain, G.M. Hart, C.M. Devan, C.M. Prager, D.}

Flynn, F.S. Ahrestani, D.E. Bunker, M.I. Palmer, S.M. Smukler, J. Sircely, and S. Naeem 


\section{Rare Species}

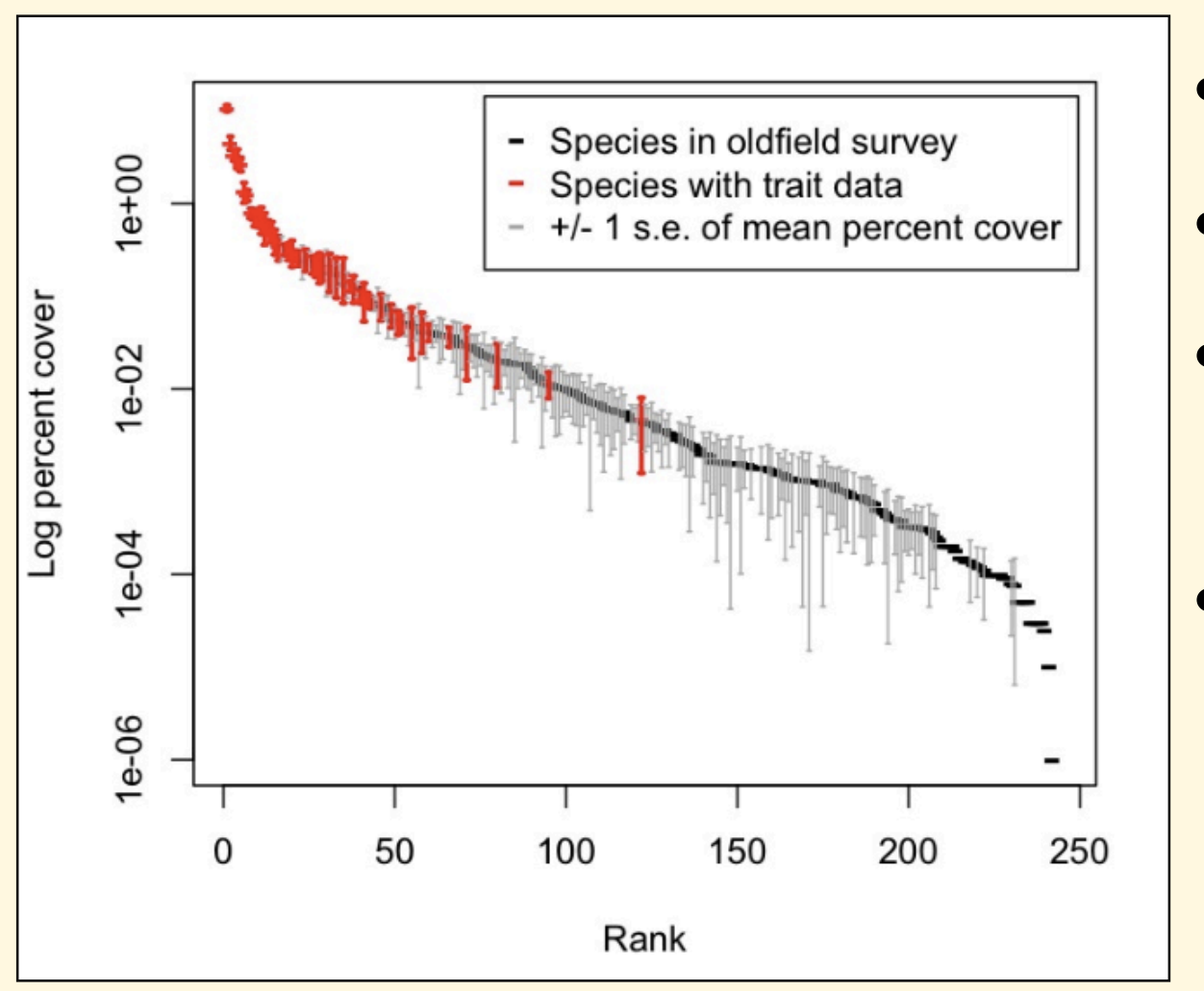

- Majority of species are rare

- Prone to extinction

- Functional impacts of their loss is unknown

- Importance under changing environmental conditions 
How do rare species contribute to functional

\section{diversity?}




\section{Study Site}

- Cedar Creek Ecosystem Science Reserve (LTER Network)

- 46 species with suitable trait data

-248 total

- Trait data collected in 2006

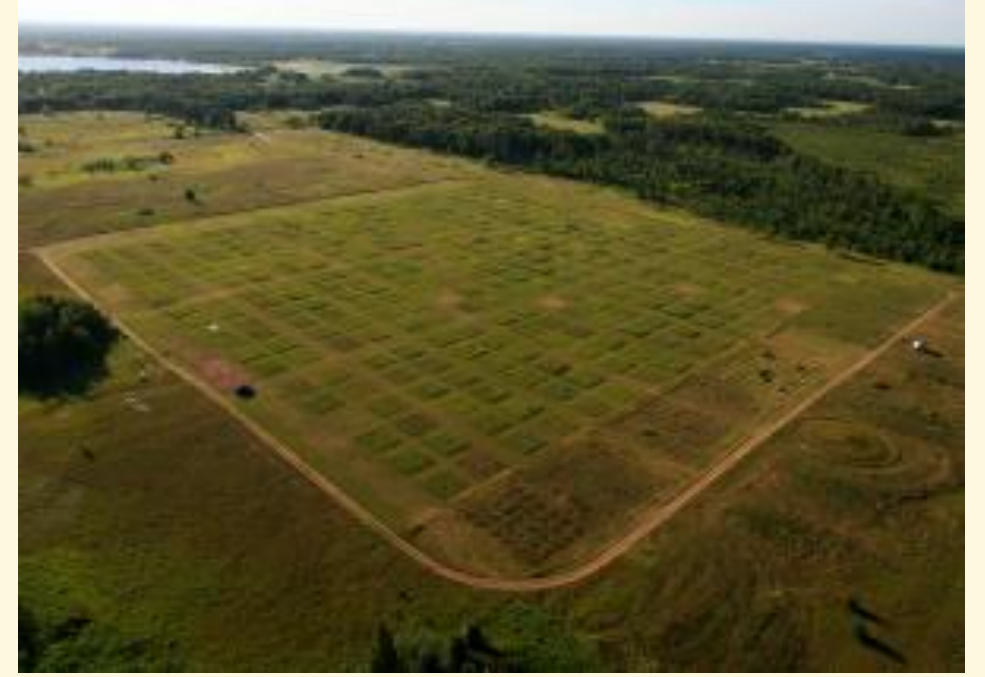

(c) www.cedarcreek.unm.edu 


\section{Functional Trait Selection and Collection}

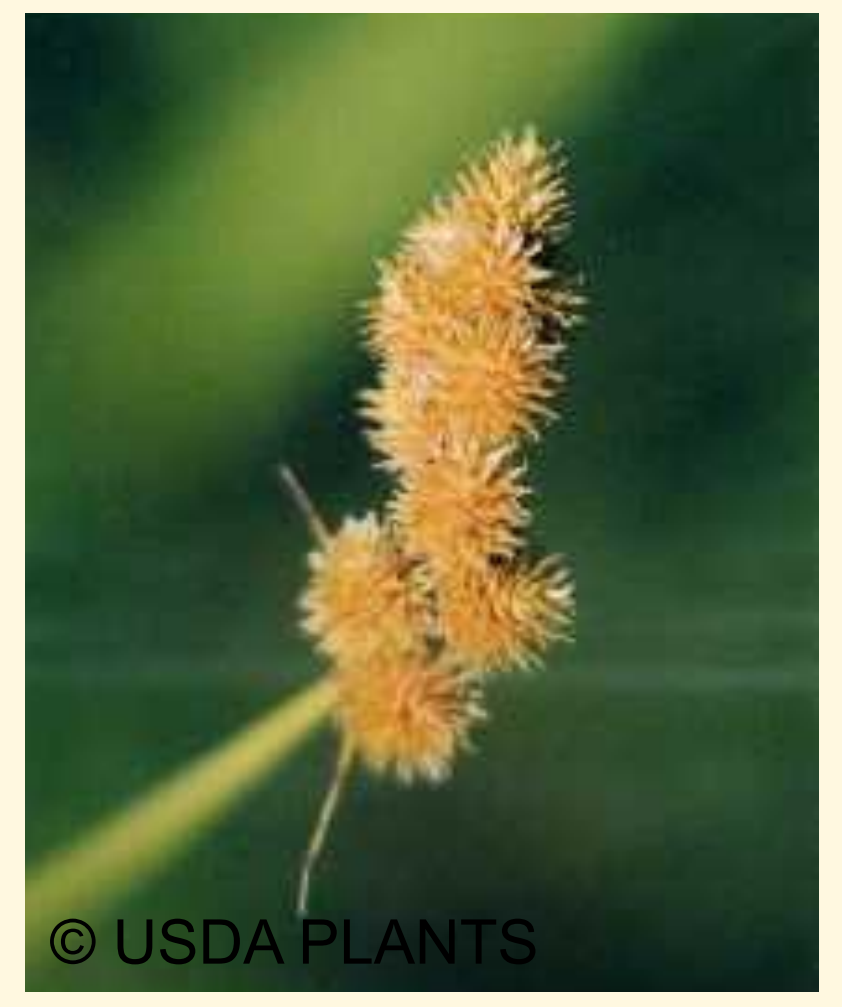

- Plant Traits

- Total plant mass

- Root:Shoot

- Leaf Mass per Area (LMA)

- Percent Leaf Nitrogen (\%N)

- Field Sampling

- Six individuals of each species

- Measurements completed near peak of vegetative growth 


\section{Defining Rarity}

- Geographic range

- Number of states and Canadian provinces the species occurs in (USDA PLANTS database)

- Habitat Specificity

- Floristic Quality Assessment Index (FQAI)

- Mean Abundance

- Maximum Abundance

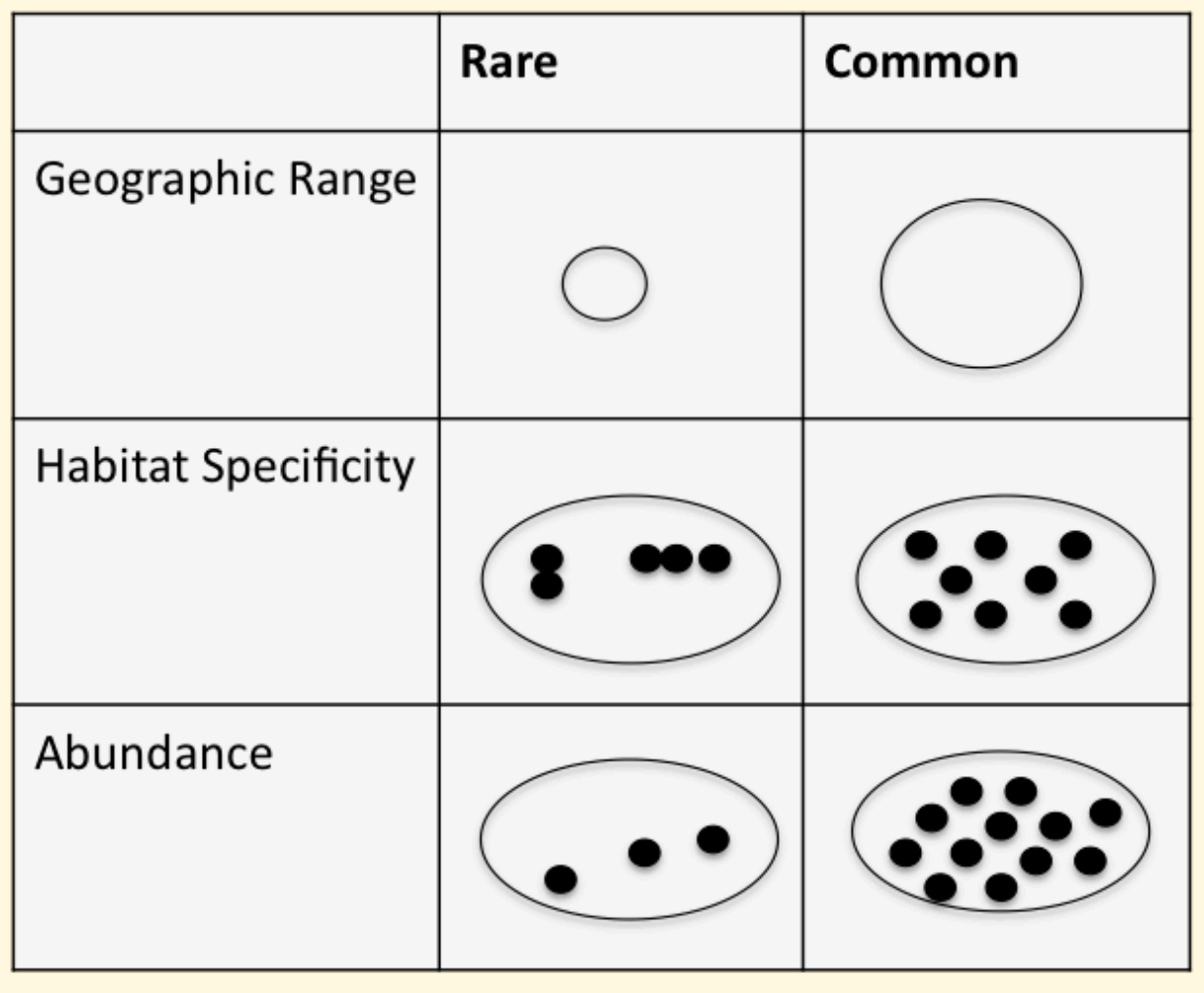

Based on Rabinowitz 1981 


\section{Convex Hull Volume}

- Trait values for each species plotted on separate axes

- Minimum multivariate trait space of a group of species

- Reflects community assembly and can be a proxy for potential

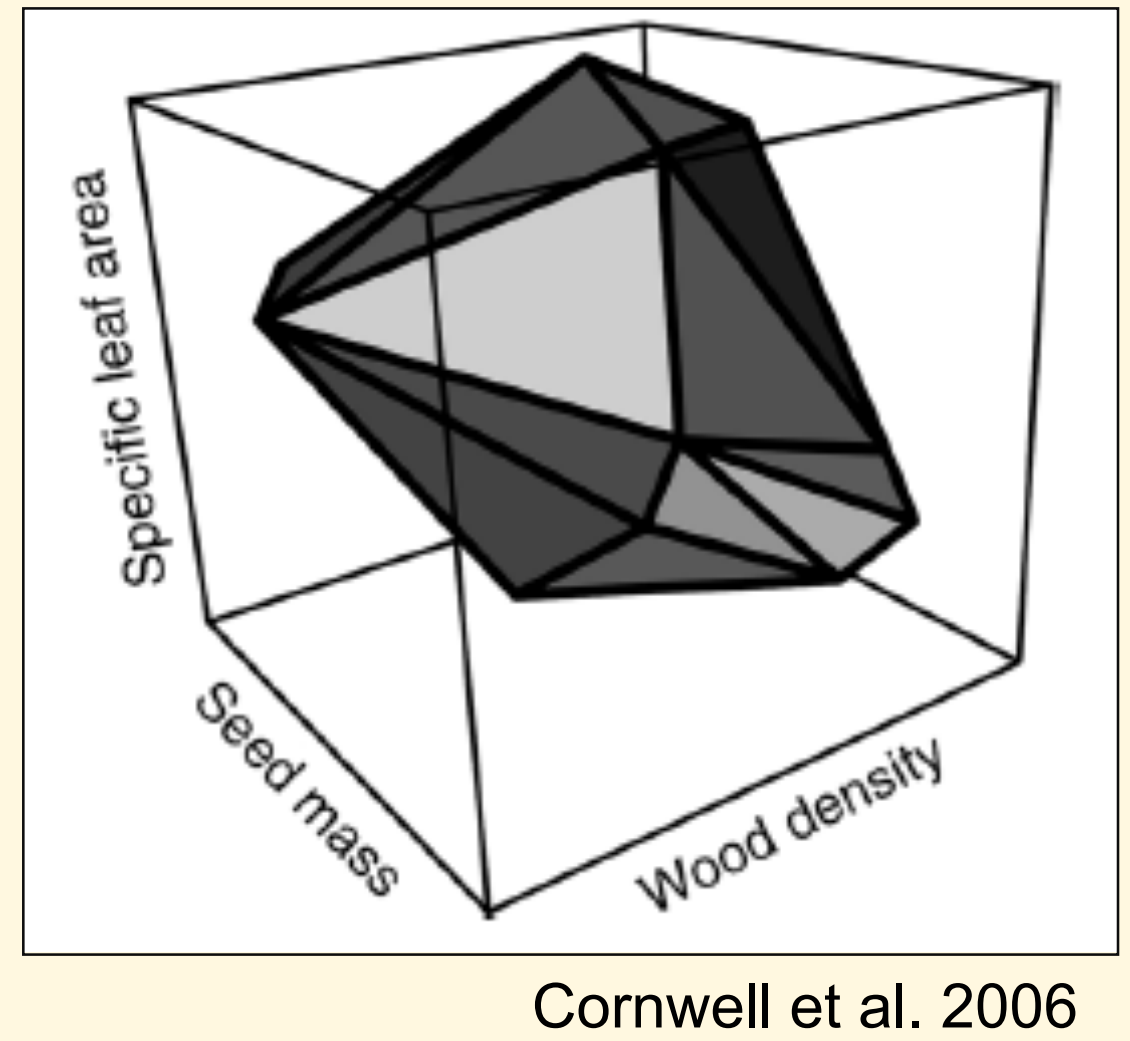
ecosystem functioning 


\section{Rare and Common Species:}

\section{Contributions to Convex Hull Volume}

- Traits of rare species are redundant with those of common species (A)

- Rare and common species have similar traits (B)

- Rare species have different traits than common species (C)

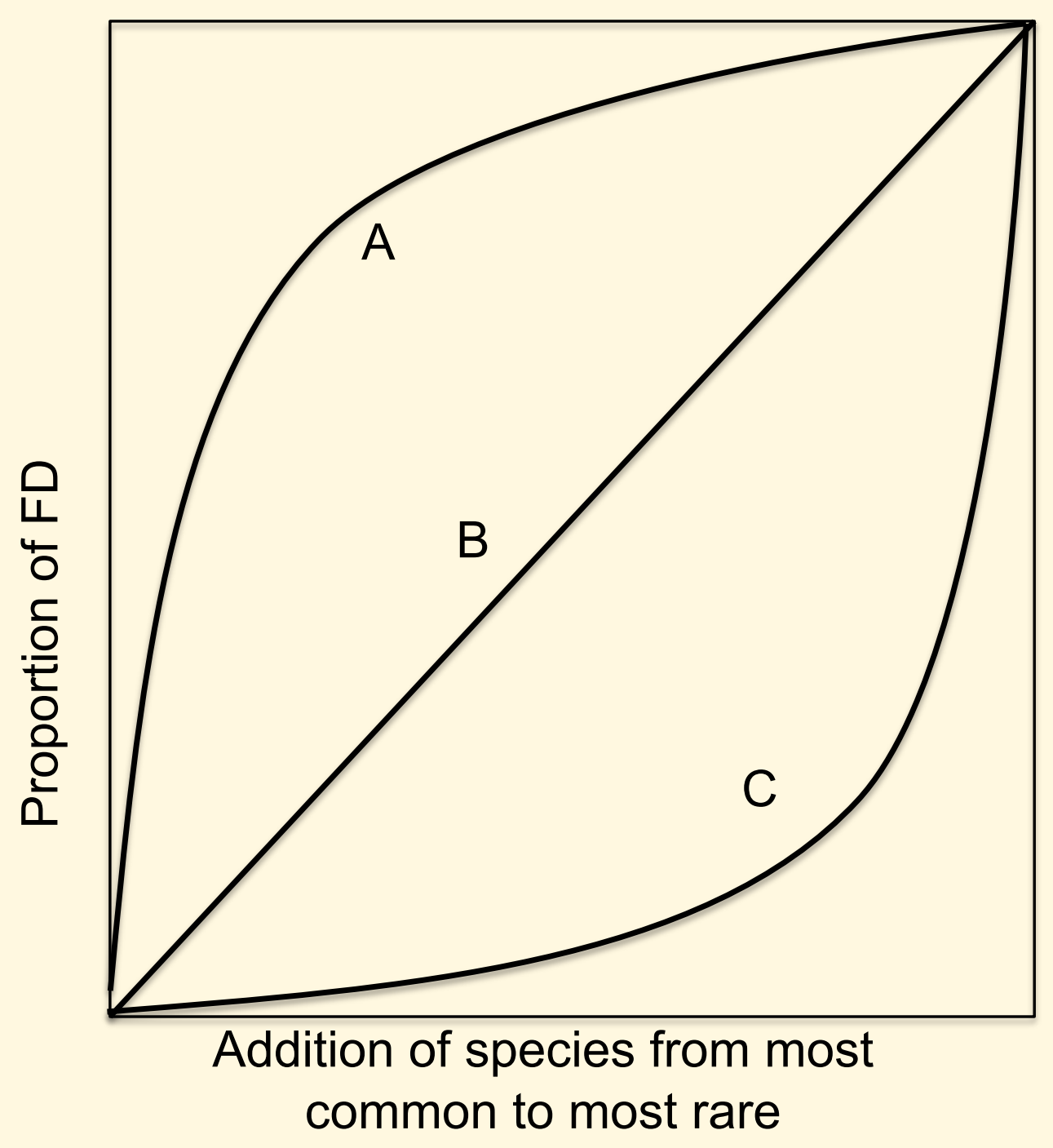




\section{Data Analysis}

1) Convex hull methodology

1) Total functional trait space volume

2) Remove and replace species, calculate change in hull volume

2) Contribution to trait space

3) Species ranked from most common to most rare-regression performed on contribution to trait space and rarity rank 


\section{Mean Abundance}

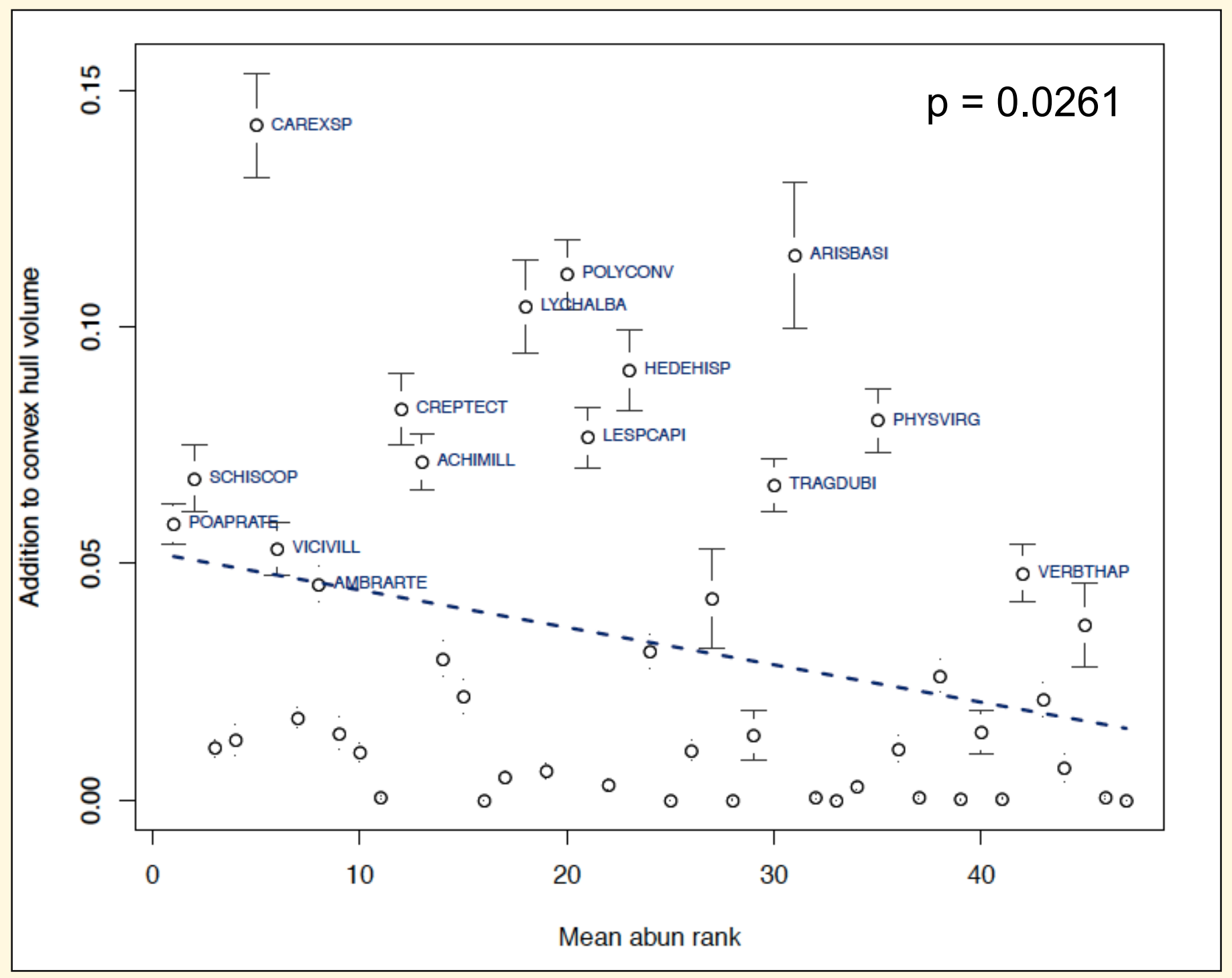




\section{Maximum Abundance}

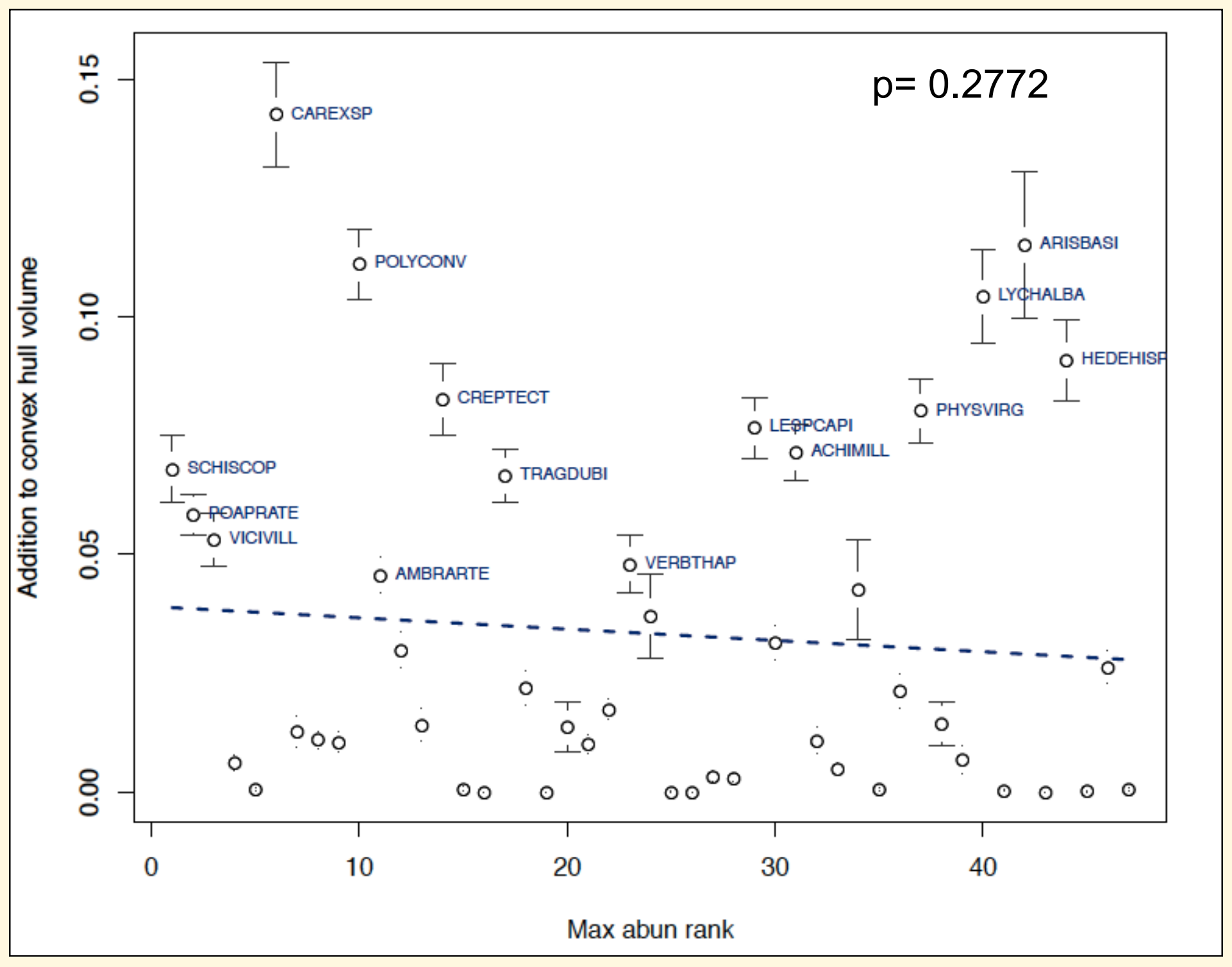




\section{Geographic Range}

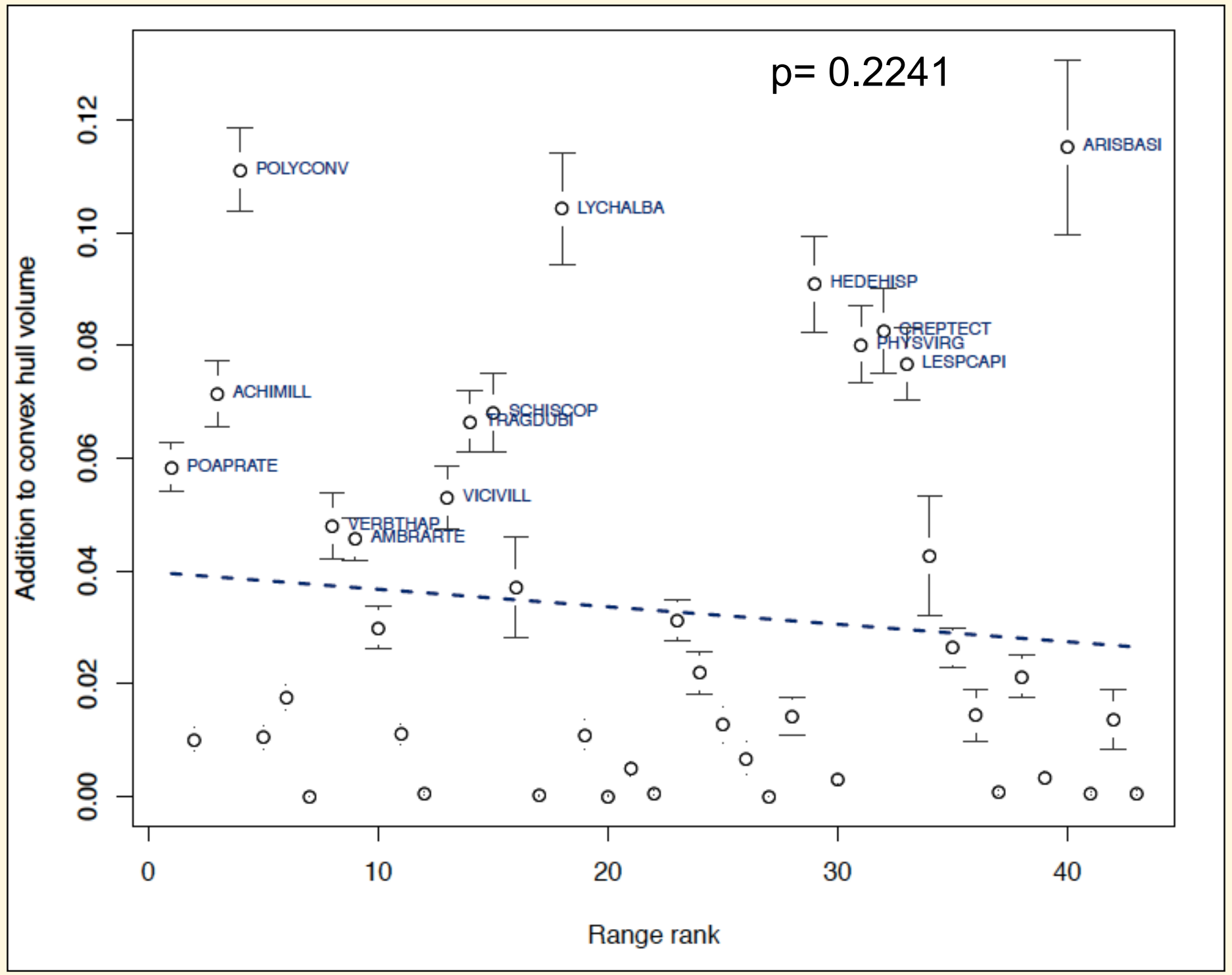




\section{Habitat Specificity}

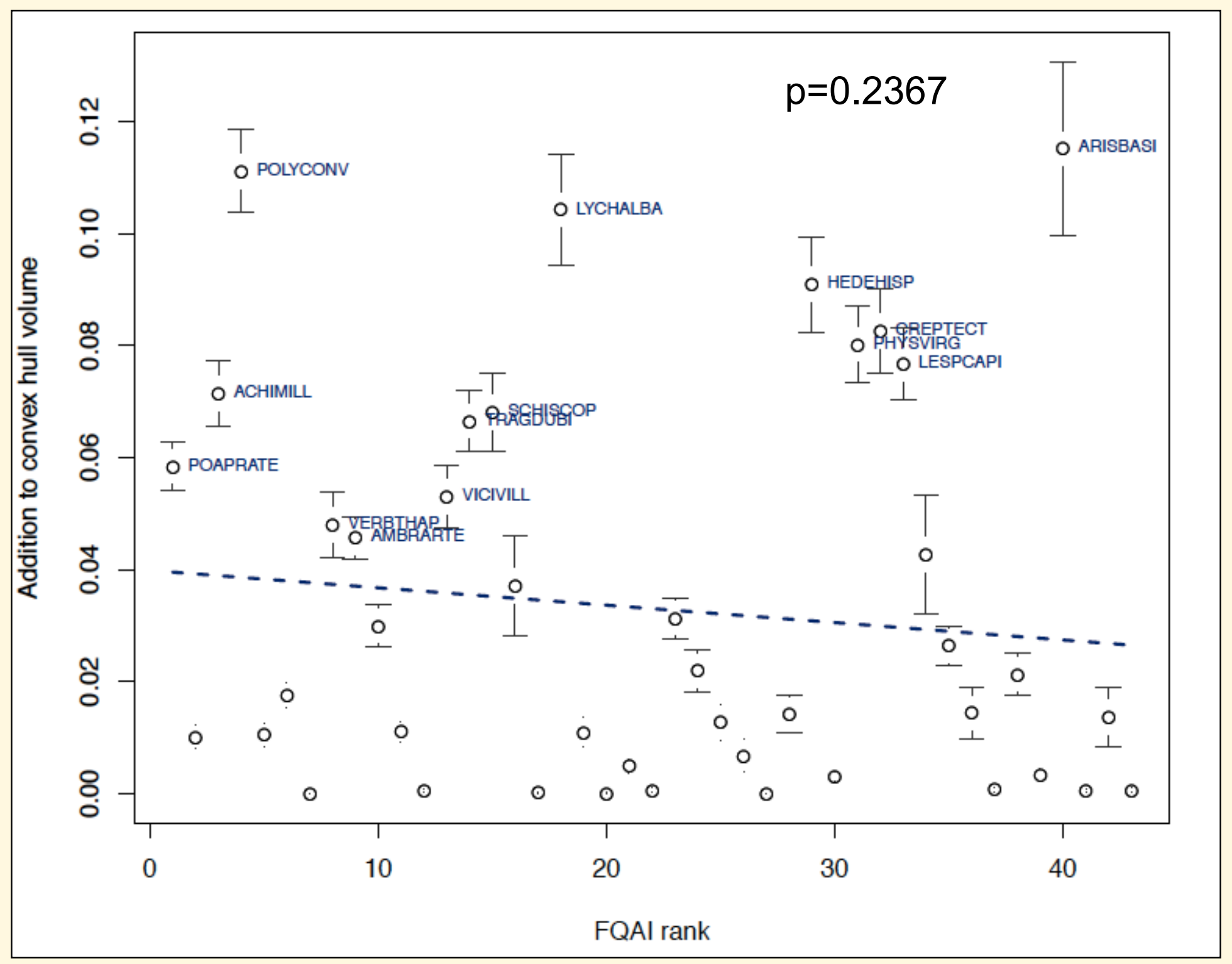




\section{Summary}

- Negative relationship between functional diversity and maximum abundance

- Trait distinctiveness

- Excluding maximum abundance, rare species equally as likely to contribute to functional trait space

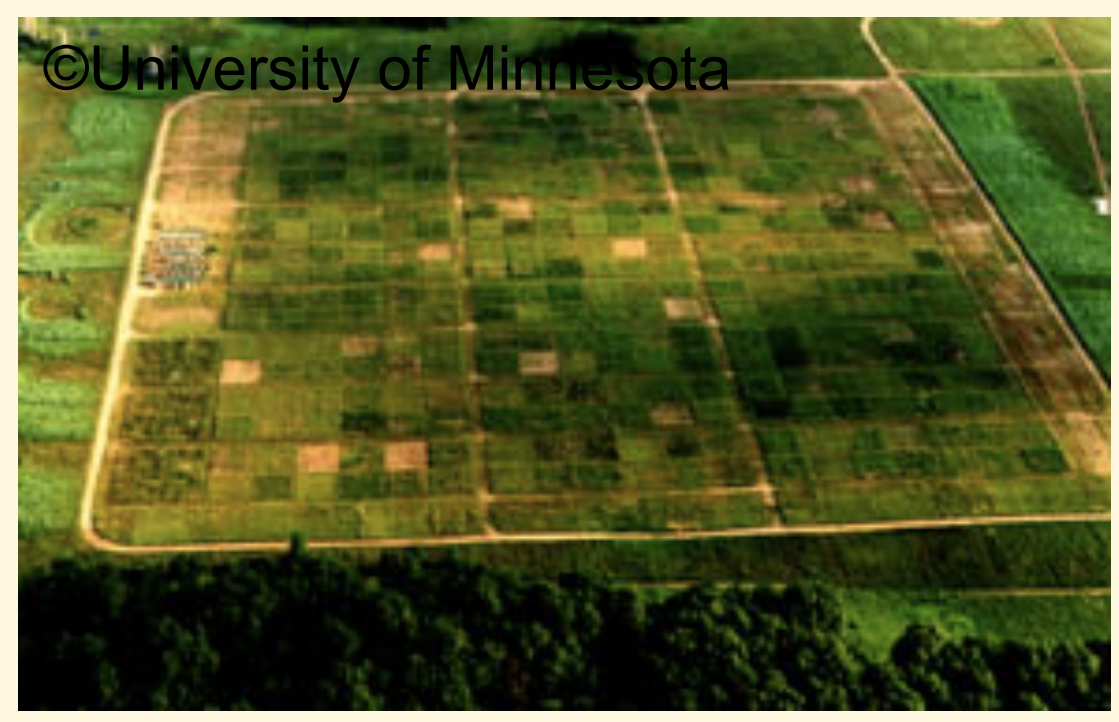




\section{Implications and Future Directions}

- Consequences for ecosystem functioning?

- Experimental communities

- Causes of rarity and commonness with respect to trait distinctness

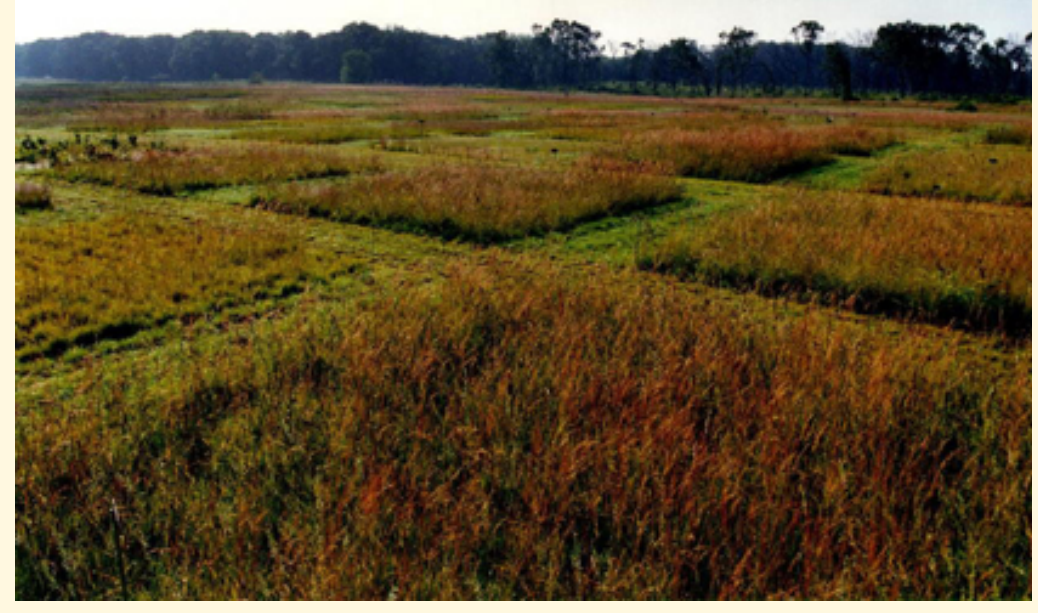

Chttp://www.cedarcreek.umn 


\section{Acknowledgements}

- Jean Knopps and Dan Bunker for trait data collection

- Cedar Creek LTER

- Naeem Lab

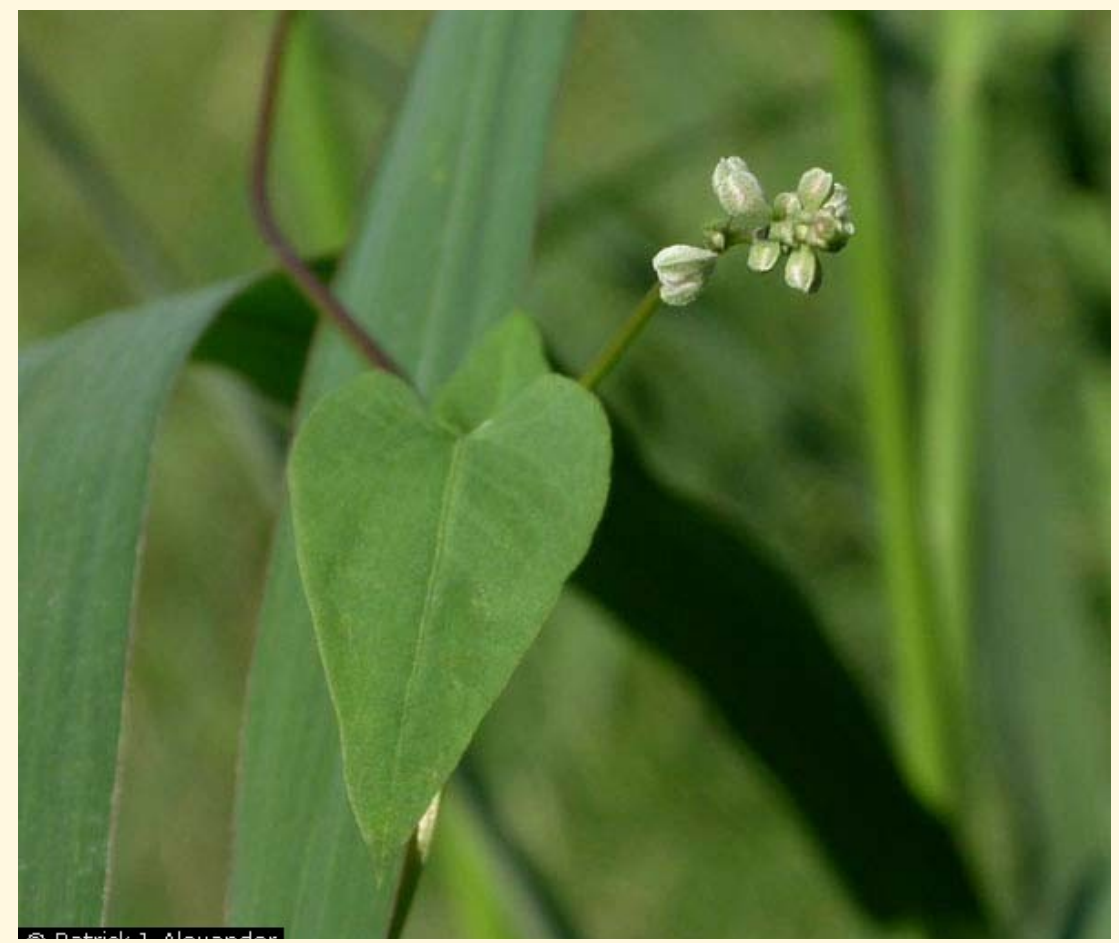

